\title{
Bandwidth Shaping Menggunakan Proxy Squid
}

\author{
${ }^{1}$ Dwi Yatmoko Siambudi , ${ }^{2}$ Wamiliana, ${ }^{3}$ Wisnu Wardhana \\ ${ }^{1}$ Jurusan Ilmu Komputer Fakultas MIPA Unila \\ 2 Jurusan Matematika Fakultas MIPA Unila \\ ${ }^{3}$ Linux Lampung Group
}

\begin{abstract}
The development of technology is very fast. Nowadays, technology has influenced human life. For most people, handphone and computer now become a necessity. Computer can give information as we need with internet, but internet can cause a negative influence as well. In this research, we build an web base application which can block a negative-influence sites using Squid Proxy. Squid is a daemon that used as a proxy server and web cache. It can work as a connection sharing, filtering and caching. The web which domain block is successfully built which can create a bandwidth share and domain block web base application.
\end{abstract}

Keyword: bandwidth, proxy, Squid, server, website, domain block, proxy server, GNU/Linux, Debian.

\section{Pendahuluan}

Perkembangan teknologi sudah sangatlah pesat. Pada saat ini teknologi sudah sangat menjamur di setiap sisi kehidupan manusia. Handphone dan komputer sekarang sudah menjadi kebutuhan untuk sebagian banyak orang dari berbagai tingkatan kehidupan.

Komputer adalah seperangkat alat yang terdiri dari input, proses dan output yang berguna untuk memudahkan manusia dalam melakukan kegiatan sehari-hari, seperti membuat surat, membuat laporan penelitian dan lain sebagainya. Hardware adalah komponen pada komputer yang dapat terlihat dan disentuh secara fisik, misalnya motherboard, mouse, keyboard dan lain-lain. Software adalah data elektronik yang disimpan oleh komputer itu dapat berupa program atau instruksi yang akan menjalankan suatu perintah, seperti Microsoft Word, pemutar musik, pemutar video. Komputer juga dapat membantu dalam pembuatan website atau sistem informasi untuk perusahaan dan institusi tertentu.

Komputer dapat membantu dalam pekerjaan dan juga memberikan informasi yang diinginkan dengan menggunakan internet. Internet dapat saja memberikan dampak positif dan juga dampak negatif bagi penggunanya. Bagi orang tua, tentu saja tidak ingin apabila anaknya mendapatkan dampak yang negatif dengan adanya internet, maka dari itu penelitian ini membahas tentang pembuatan website yang dapat memblokir situs yang dapat berdampak buruk bagi penggunanya menggunakan Squid proxy.

Website atau yang biasa disebut web dapat diartikan sebagai suatu kumpulan-kumpulan halaman yang menampilkan berbagai macam informasi teks, data, gambar diam ataupun bergerak, data animasi, suara, video maupun gabungan dari semuanya, baik itu yang bersifat statis maupun yang 
dinamis, yang dimana membentuk satu rangkaian bangunan yang saling berkaitan dimana masing-masing dihubungkan dengan jaringan halaman.

Squid adalah software publik Domain berbasis UNIX. Fungsi dari Squid adalah meng-'cache' atau menyimpan data yang diminta oleh pengguna (komputer client) biasanya berupa webpages dan FTP. Platform UNIX yang di support oleh Squid adalah FreeBSD, BSDI, Digital Unix, Irix, Linux, Solaris dan SunOs. Tidak semua data bisa di cache oleh Squid. Data-data yang bersifat dinamik seperti CGI-BIN tidak di cache oleh Squid, sehingga tiap kali ada permintaan CGI-BIN, maka Squid akan menghubungi langsung server tujuan. Saat ini protokol yang dapat dilayani oleh Squid adalah HTTP, FTP, Gopher, dan Wais.

\section{Tinjauan Pustaka}

\section{A. Proxy}

Proxy dalam pengertiannya sebagai perantara, bekerja dalam berbagai jenis protokol komunikasi jaringan dan dapat berada pada level-level yang berbeda pada hirarki layer protokol komunikasi jaringan. Suatu perantara dapat saja bekerja pada layer Data-Link, layer Network dan Transport, maupun layer Aplikasi dalam hirarki layer komunikasi jaringan menurut OSI. Namun pengertian Proxy Server sebagian besar adalah untuk menunjuk suatu server yang bekerja sebagai Proxy pada layer Aplikasi ${ }^{[1]}$.

\section{B. Server}

Server adalah suatu sistem komputer yang menyediakan jenis layanan (service) tertentu dalam suatu jaringan komputer. Server didukung dengan prosesor yang bersifat scalable dan RAM yang besar, juga dilengkapi dengan sistem operasi khusus, yang disebut sebagai sistem operasi jaringan (network operating system). Server juga menjalankan perangkat lunak administratif yang mengontrol akses terhadap jaringan dan sumber daya yang terdapat di dalamnya, seperti halnya berkas atau alat pencetak (printer), dan memberikan akses kepada workstation anggota jaringan [2].

\section{Squid Proxy Server}

Squid proxy server adalah pelayanan yang diberikan oleh server kepada client atau user untuk menyediakan akses ke internet kepada client. Dengan squid proxy ini,kita juga bisa memblok situs situs yang berbau sara, porno, judi dan lain lain ${ }^{[3]}$.

\section{Metodologi}

A. Waktu dan Tempat Penelitian

Penelitian dilakukan di Jurusan Ilmu Komputer, Fakultas Matematika dan Ilmu Pengetahuan Alam Universitas Lampung yang beralamatkan di jalan Soemantri Brojonegoro No. 1 Gedong Meneng, Bandar Lampung. Waktu penelitian dilakukan pada semester genap tahun ajaran 20162017.

\section{B. Diagram Sistem}

Use Case diagram berikut ini menjelaskan bagaimana pengguna menggunakan system. Lihat Gambar 1. 


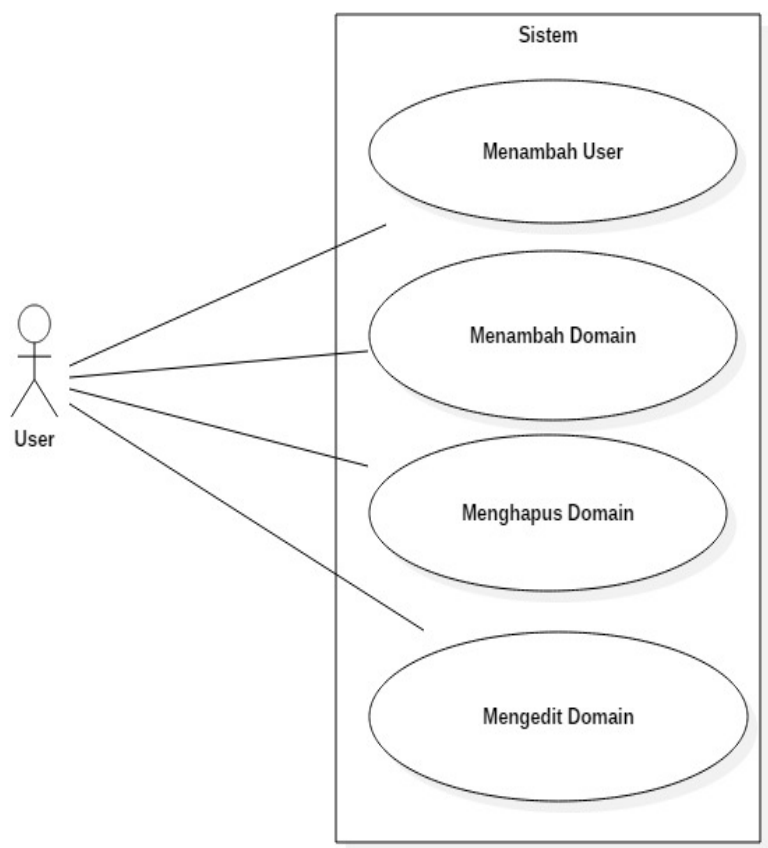

Gambar 1. Use Case Diagram

\section{Metode Pengembangan Sistem}

Penelitian dilakukan berdasarkan metode pengembangan sistem yang di pilih yaitu eXtreme Programming (XP). Tahap-tahap yang dilakukan dalam pengembangan sistem aplikasi pencarian informasi sholat Jumat ini adalah sebagai berikut.

\section{Planning}

Dalam tahap ini dikumpulkan kebutuhan awal user atau dalam XP disebut user stories. Hal ini dibutuhkan agar pengembang mengerti bisnis konten, kebutuhan output sistem, dan fitur utama dari software yang dikembangkan.

\section{Design}

Desain dari sistem pada penelitian ini digambarkan dengan model UML berupa use case diagram, activity diagram, dan relation table. Pembuatan desain pada XP tetap mengedepankan prinsip Keep it Simple (KIS). Desain di sini merupakan representasi dari sistem guna mempermudah pengembang dalam membangun sistem.

\section{Coding}

Pada tahap ini dibangun aplikasi yang menjadi objek penelitian. Aplikasi dibangun berdasarkan desain yang telah dibuat pada tahap sebelumnya. Dalam pembangunan aplikasi ini menggunakan bahasa pemrograman Java, serta XML untuk tampilan pada Android. Pada tahap coding juga disisipkan tahap refactoring. Refactoring adalah proses mengubah sistem perangkat lunak sedemikian rupa dengan tidak mengubah eksternal kode dalam memperbaiki struktur internalnya. Hal ini dilakukan untuk meminimalkan kemungkinan adanya bug. 


\section{Testing}

Pada tahap ini aplikasi yang telah dibangun diuji apakah kebutuhan awal user atau user stories sudah dipenuhi dan apabila terpenuhi aplikasi siap dirilis.

\section{Hasil Penelitian}

Sistem Bandwidth Shaping menggunakan Proxy Squid merupakan pengembangan dari penelitian milik mahasiswa Ilmu Komputer angkatan 2009 oleh saudara Fahmi Badar yang berjudul "Rancang Bangun Dan Implementasi Manajemen Bandwidth Pada Router Berbasis Sistem Operasi GNU-Linux Debian”. Sistem ini bertujuan untuk memudahkan user membagi kecepatan bandwidth dan ditambahkan dengan fungsi blokir Domain. Sistem ini mempunyai 3 menu, yaitu menu home, Pembagian Bandwidth, dan Blokir Domain. User dapat mengatur kecepatan bandwidth pada menu Pembagian Bandwidth, sedangkan untuk blokir Domain, user dapat memasukkan Domain yang ingin di blokir pada menu Blokir Domain.

\section{A. Konfigurasi Server}

IP address digunakan sebagai pengenal bagi komputer dalam suatu jaringan. Pemberian alamat IP address pada kartu jaringan dapat diberikan secara static dan dynamic, berikut adalah cara mengatur pemberian alamat IP permanen dengan cara static pada sistem Operasi Linux Debian.

Buka file "etc/network/interfaces" dengan mengetikkan di terminal \#nano /etc/network/interfaces

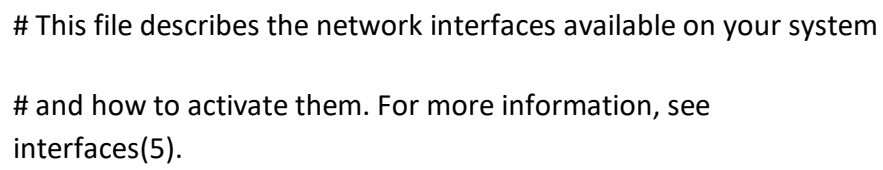

Lalu dimodifikasi menjadi

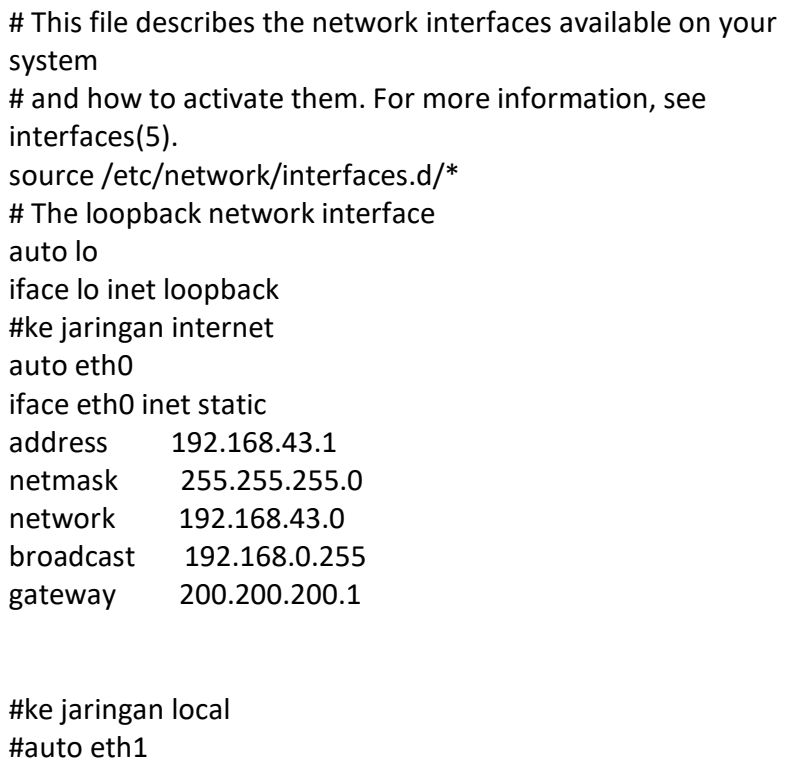


Simpan file tersebut dengan mengetikkan $\mathrm{CTRL}+\mathrm{O}$ dan tutup dengan mengetikkan $\mathrm{CTRL}+\mathrm{X}$. Konfigurasi diatas menunjukkan bahwa alamat IP yang akan dikenali pada kartu jaringan (eth0) adalah 192.168.43.1, sedangkan alamat IP yang akan dikenali pada kartu jaringan (eth1) adalah 192.168.6.1. kartu jaringan (eth0) akan terkoneksi ke internet, sedangkan kartu jaringan (eth1) yang akan menjadi server. Setelah melakukan pengaturan pada alamat IP, restart jaringan dengan mengetikkan di terminal

\section{\#service networking restart}

Perintah ini berfungsi agar pengaturan IP bisa di aplikasikan pada komputer.

\section{B. Mengatur NAT}

NAT (Network Address Translation) adalah metode untuk menghubungkan komputer ke internet menggunakan suatu alamat IP. Untuk dapat mengatur konfigurasi NAT ketikkan pada terimal

\#nano /etc/rc.local

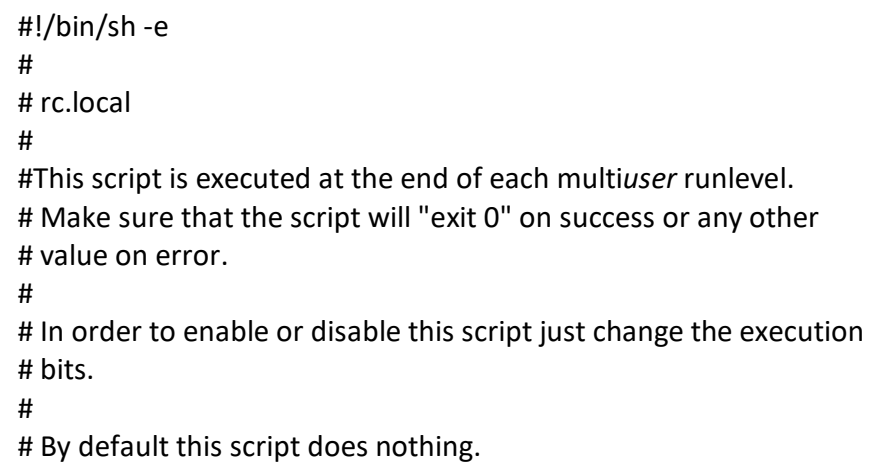

Modifikasi file tersebut menjadi seperti di bawah ini

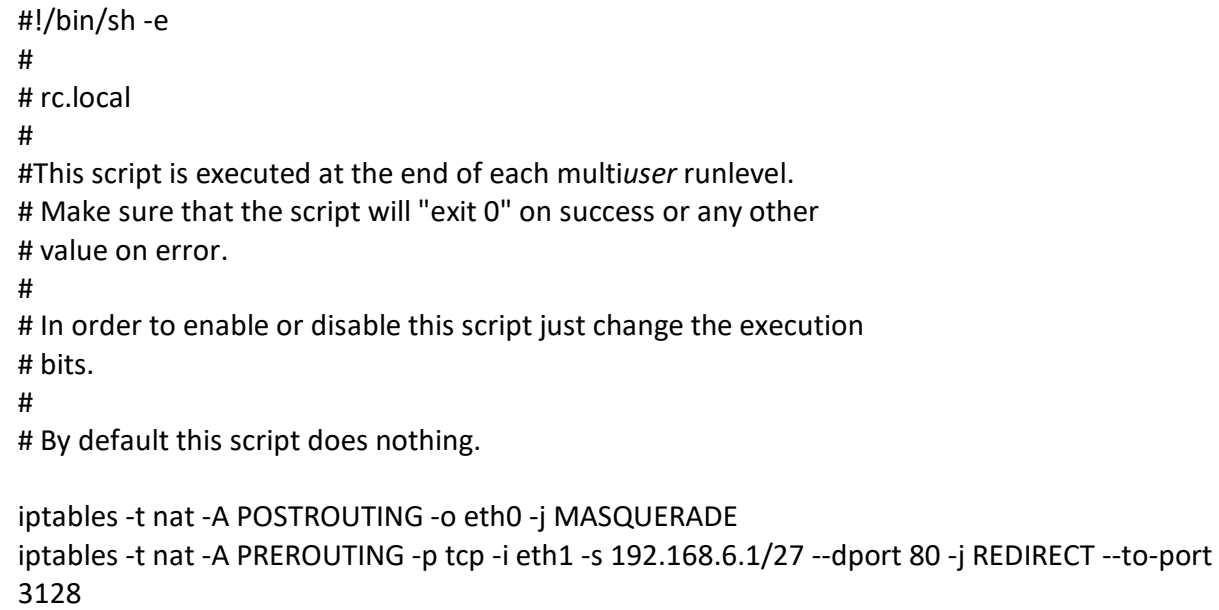

Jika selesai, simpan file, maka komputer server sekarang sudah bisa meneruskan akses internet ke client. 
Vol 6 No. 1, 2018

(c2018 Ilmu Komputer Unila Publishing Network all right reserve

Jurnal Komputasi

\section{Install Squid}

Langkah pertama yang dilakukan adalah install squid terlebih dahulu, ketikkan perintah

\#apt-get install squid3

Jika pemasangan selesai, buka file konfigurasi squid yang ada pada direktori squid, untuk melihat isi file squid, ketikkan perintah berikut:

\#nano /etc/squid3/squid.conf

Lalu akan terbuka file konfigurasi default dari squid.

D. Hasil Pengujian Bagi Bandwidth

Pengujian ini dilakukan untuk membuktikan apakah proses pembagian bandwidth dapat berjalan sesuai keinginan user, apakah bandwidth dapat terbagi sama rata untuk setiap user, salah satu cara mengetahuinya adalah dengan melakukan download file pada user dan melihat kecepatan transfer data apakah sama atau berbeda.

Langkah awal yang harus dilakukan adalah memasukkan nilai yang diinginkan untuk membagi kecepatan bandwidth secara merata ke semua user, setelah memasukkan nilai lalu dilakukan pengujian berupa download file yang sama oleh 2 client, client pertama menggunakan sistem operasi Linux, client kedua menggunakan sistem operasi Windows. Lihat pada Gambar 2 dan 3.

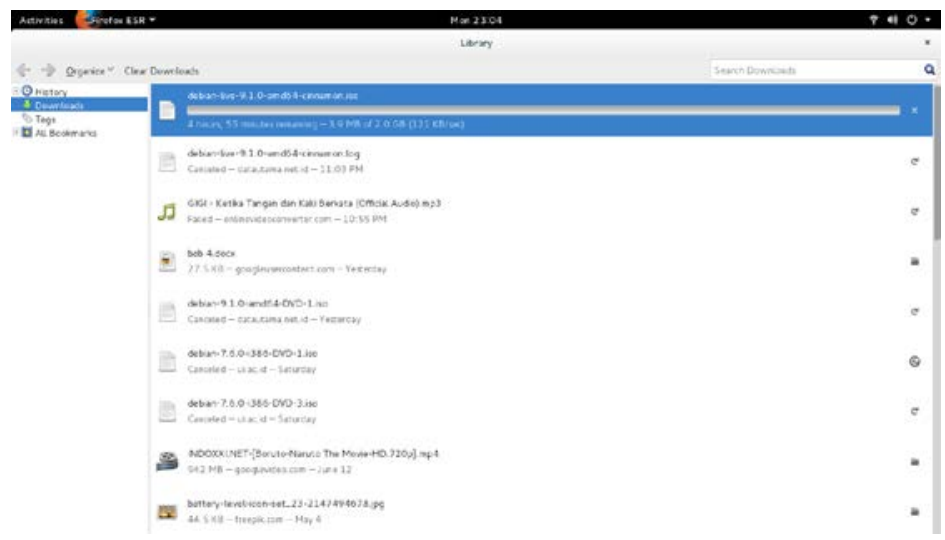

Gambar 2. Hasil Download Client 1

Pengujian Membagi Bandwidth pada client 1 dapat dilihat bahwa kecepatan download adalah 121 $\mathrm{KB} / \mathrm{sec}$.

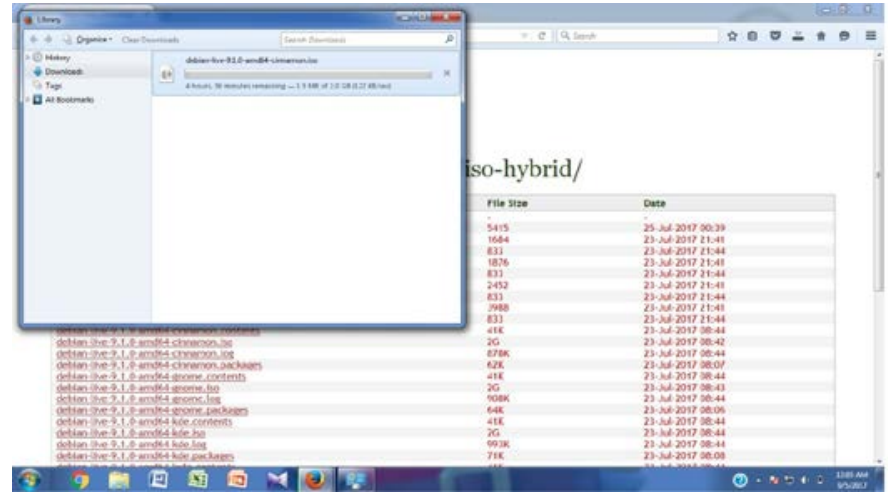

Gambar 3. Hasil Download Client 2 
Pengujian Download pada client 2 yang menggunakan sistem operasi Windows memperlihatkan bahwa kecepatan download adalah $122 \mathrm{~KB} / \mathrm{sec}$, yang berarti bahwa kecepatan download client 1 dan 2 sama, ini menunjukkan bahwa pembagian bandwitdh berjalan sesuai dengan yang diharapkan.

\section{E. Hasil Pengujian Blokir Domain.}

Pengujian ini dilakukan untuk membuktikan apakah proses pemblokiran Domain bisa berjalan dengan baik dengan cara mengakses alamat yang diblokir dan apakah pengguna bisa mengakses alamat tersebut.

Langkah awal pengujian yaitu dengan memasukkan Domain yang ingin di blokir, setelah memasukkan Domain yang diinginkan. Akses Domain yang telah di blok. Lihat Gambar 5 dan 6.

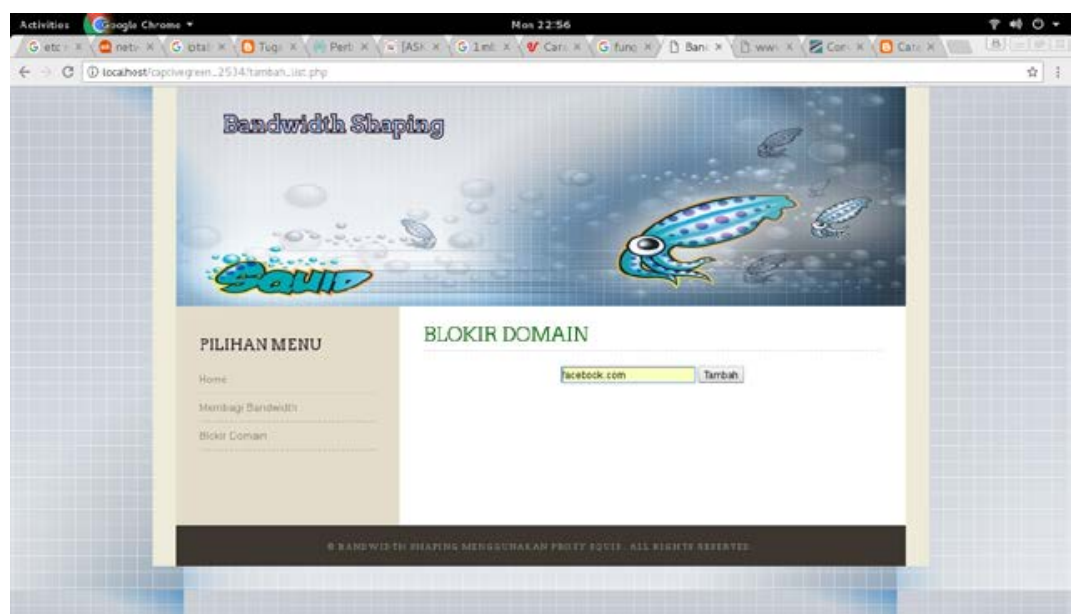

Gambar 5. Masukkan Domain

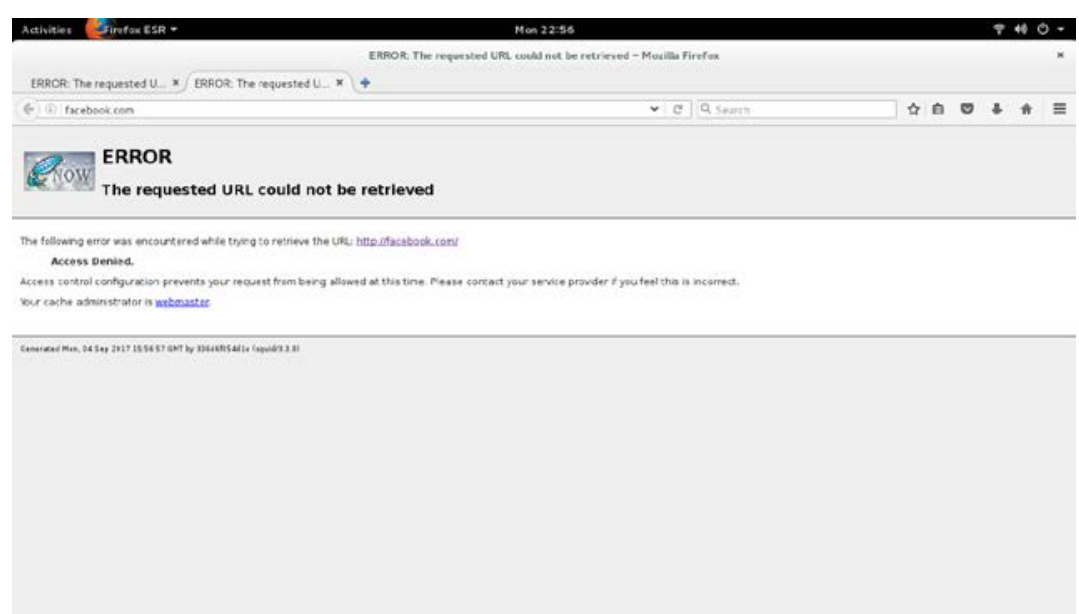

Gambar 6. Domain Terblokir

Pada pengujian yang telah dilakukan, terlihat pada Gambar 4.9 bahwa Domain facebook.com tidak dapat diakses dan menampilkan pesan error yang menunjukkan bahwa Domain telah berhasi terblokir. 


\section{Kesimpulan}

Berdasarkan penelitian yang telah dilakukan, dapat disimpulkan bahwa telah erhasil membuat Interface pembagian bandwidth dan blokir Domain berbasis Web, aplikasi ini dapat melakukan pembagian Bandwidth dan memvlokir Domain sesuai dengan nilai yang diinputkan oleh user, namun Squid masih memiliki kelemahan yaitu tidak dapat memblokir https.

\section{.Reference}

[1] Arjuni, Sandy. 2010. Perancangan dan Implementasi Proxy server dan Manajemen Bandwidth Menggunakan Linux Ubuntu Server. (Studi Kasus di Kantor Manajemen PT.Wisma Bumiputera Bandung). Tugas Akhir. Tidak diterbitkan. Institut Teknologi Bandung: Bandung.

[2] Ardiansyah Rusmana, Anbar, 2011. Implementasi Jaringan Labotorium Komputer di SMPN 1 TAMBUN Selatan Sebagai Penunjang Kegiatan Belajar Mengajar, Tugas Akhir. Tidak diterbitkan. Politeknik Telkom: Bandung.

[3] Wagito. 2007. Jaringan Komputer (Teori dan Implementasi Berbasis Linux). Yogyakarta: Gava Media. 